Article

\title{
On a Viscosity Iterative Method for Solving Variational Inequality Problems in Hadamard Spaces
}

\author{
Kazeem Olalekan Aremu, Chinedu Izuchukwu, Hammed Anuolwupo Abass \\ and Oluwatosin Temitope Mewomo*(i)
}

School of Mathematics, Statistics and Computer Science, University of KwaZulu-Natal, Durban 4001, South Africa; 218081063@stu.ukzn.ac.za or aremukazeemolalekan@gmail.com (K.O.A.); izuchukwu_c@yahoo.com or izuchukwuc@ukzn.ac.za (C.I.); 216075727@stu.ukzn.ac.za (H.A.A.)

* Correspondence: mewomoo@ukzn.ac.za

Received: 24 October 2020; Accepted: 18 November 2020; Published: 16 December 2020

\begin{abstract}
In this paper, we propose and study an iterative algorithm that comprises of a finite family of inverse strongly monotone mappings and a finite family of Lipschitz demicontractive mappings in an Hadamard space. We establish that the proposed algorithm converges strongly to a common solution of a finite family of variational inequality problems, which is also a common fixed point of the demicontractive mappings. Furthermore, we provide a numerical experiment to demonstrate the applicability of our results. Our results generalize some recent results in literature.
\end{abstract}

Keywords: variational inequalities; inverse strongly monotone mappings; demicontractive mappings; fixed point problems; Hadamard spaces

MSC: 47H06; 47H09; 47J05; 47J25

\section{Introduction}

The classical variational inequality problem (VIP) is defined in a real Hilbert space setting as: find $x \in D$ such that

$$
\langle T x, y-x\rangle \geq 0 \forall y \in D,
$$

where $T$ is a nonlinear operator defined on $D$ and $D$ is a nonempty subset of the Hilbert space. The theory of VIP combines concepts of nonlinear operators and convex analysis in such a way that it generalizes both and is used to model nonlinear problems of physical phenomena in economics, sciences and engineering (see [1] for details). The VIP (1) was first introduced in finite dimensional spaces by Stampacchia [2], and since then researchers have devoted a lot of attention to VIP in finite and infinite dimensional spaces (see [3-8] and other references therein). Another form of the VIP widely studied in real Hilbert space settings (see $[9,10]$ and the references therein) is defined as: find $x \in D$ such that

$$
\langle x-T x, y-x\rangle \geq 0 \forall y \in D .
$$

Several algorithms have been developed for solving VIP and related optimization problems in Hilbert and Banach spaces (see [3,7,11-16] and other references therein). It is well known that many of the problems in practical applications of optimization are constrained optimization problems, where the constraints are nonlinear, non-convex and non-smooth. Hence, it is pertinent to extend the study of these optimization problems to the nonlinear space settings, due to its ability to see non-convex and non-smooth constrained optimization problems as convex, smooth and unconstrained problems. 
For this reason, Németh [17] introduced and generalized the existence and uniqueness results of the classical VIP from Euclidean spaces to complete Riemannian manifolds. This development led to increasing interest from researchers in the study of VIPs and their generalizations in nonlinear spaces (see [18-27] and other references therein). Despite the increasing attention of researchers in this direction, little attention has been given to other more general nonlinear spaces apart from the Riemannian manifolds. In 2015, Khatibzadeh and Ranjbar [28] extended the study of VIP (2) to the framework of complete CAT(0) spaces. They formulated the VIP as follows:

$$
\text { Find } x \in D \text { such that }\langle\overrightarrow{T x x}, \vec{x} \vec{y}\rangle \geq 0 \forall y \in D \text {, }
$$

where $D$ is a nonempty, closed and convex subset of an Hadamard space $X$ and $T$ is a nonexpansive mapping. They established the existence of solutions for the VIP (3) and also employed an inexact proximal point algorithm to approximate a fixed point of the nonexpansive mapping which is also a solution of (3). They obtained convergence result for the algorithm under suitable conditions on the control sequences. Very recently, Alizadeh-Dehghan-Moradlou [29] introduced the notion of inverse strongly monotone mappings in metric spaces as follows: Let $D$ be a nonempty subset of a metric space $X$ and $T: D \rightarrow X$ be a mapping. $T$ is called $\alpha$-inverse strongly monotone if there exists $\alpha>0$ such that

$$
d^{2}(x, y)-\langle\overrightarrow{T x T y}, \overrightarrow{x y}\rangle \leq \alpha \Phi_{T}(x, y), \forall x, y \in D
$$

where $\Phi_{T}(x, y)=d^{2}(x, y)+d^{2}(T x, T y)-2\langle\overrightarrow{T x T y}, \overrightarrow{x y}\rangle$.

Additionally, in [29], the authors studied the VIP (3) in an Hadamard space, where $T$ is an inverse strongly monotone mapping. They established the existence of solutions for the VIP (3) associated with an inverse strongly monotone mapping. Furthermore, they introduced the following iterative algorithm to solve the VIP (3): for arbitrary $x_{1} \in D$, the sequence $\left\{x_{n}\right\}$ is generated by

$$
\left\{\begin{array}{l}
y_{n}=P_{D}\left[\beta_{n} x_{n} \oplus\left(1-\beta_{n}\right) T x_{n}\right], \\
x_{n+1}=P_{D}\left[\alpha_{n} x_{n} \oplus\left(1-\alpha_{n}\right) S x_{n}\right], n \geq 1,
\end{array}\right.
$$

where $\left\{\beta_{n}\right\}$ and $\left\{\alpha_{n}\right\} \in(0,1), P_{D}$ is a metric projection, $T$ is inverse strongly monotone and $S$ is nonexpansive mapping. They obtained that Algorithm (5) $\Delta$-converges to a solution of the VIP (3), which is also a fixed point of the nonexpansive mapping $S$.

Very recently, Osisiogu et al. [30] proposed and studied the following Halpern-type algorithm in Hadamard spaces for approximating a common solution of a finite family of the VIP (3):

$$
\left\{\begin{array}{l}
y_{n}=\bigoplus_{i=1}^{N} \beta_{i} P_{D} T_{\lambda_{i}} x_{n}, \\
x_{n+1}=\alpha_{n} u \oplus \beta_{n} x_{n} \oplus \gamma_{n} S y_{n} \quad \forall n \geq 1,
\end{array}\right.
$$

where $T_{\lambda_{i}}=\left(1-\lambda_{i}\right) x \oplus \lambda_{i} T x, 0<\lambda_{i}<2 \alpha_{i}$, for each $i=1,2, \cdots, N,\left\{\beta_{n}\right\},\left\{\alpha_{n}\right\}$ and $\left\{\gamma_{n}\right\} \in(0,1)$, $T$ is an inverse strongly monotone mapping and $S$ is a nonexpansive mapping. They obtained a strong convergence result of Algorithm (6) under some suitable conditions.

Motivated by the results of Khatibzadeh and Ranjbar [28], Alizadeh-Dehghan-Moradlou [29] and Osisiogu et al. [30], we propose and study a viscosity iterative algorithm (from the fact that viscosity-type algorithms converge faster than Halpern-type algorithms and also Halpern-type algorithms are particular cases of viscosity-type algorithms, see [31,32]) that comprises of a finite family of inverse strongly monotone mappings (3) and a finite family of Lipchitz demicontractive mappings in an Hadamard space. Additionally, we establish that the proposed algorithm converges strongly to a common solution of a finite family of VIPs, which is also a common fixed point of a finite family of Lipchitz demicontractive mappings in the framework of Hadamard spaces. Furthermore, we provide a 
numerical experiment to demonstrate the applicability of our results. Our result generalizes the works of Alizadeh-Dehghan-Moradlou [29] and Osisiogu et al. [30] and other similar works in literature.

\section{Preliminaries}

Let $(X, d)$ be a metric space, $x, y \in X$ and $I=[0, d(x, y)]$ be an interval. A curve $c$ (or simply a geodesic path) joining $x$ to $y$ is an isometry $c: I \rightarrow X$ such that $c(0)=x, c(d(x, y))=y$ and $d\left(c(t), c\left(t^{\prime}\right)\right)=\left|t-t^{\prime}\right|$ for all $t, t^{\prime} \in I$. The image of a geodesic path is called the geodesic segment, which is denoted by $[x, y]$ whenever it is unique. We say that a metric space $X$ is a geodesic space if for every pair of points $x, y \in X$, there is a minimal geodesic from $x$ to $y$. A geodesic triangle $\Delta\left(x_{1}, x_{2}, x_{3}\right)$ in a geodesic metric space $(X, d)$ consists of three vertices (points in $\left.X\right)$ with geodesic segments between each pair of vertices. For any geodesic triangle, there is a comparison (Alexandrov) triangle $\bar{\Delta} \subset \mathbb{R}^{2}$ such that $d\left(x_{i}, x_{j}\right)=d_{\mathbb{R}^{2}}\left(\bar{x}_{i}, \bar{x}_{j}\right)$ for $i, j \in\{1,2,3\}$. A geodesic space $X$ is a CAT( 0$)$ space if the distance between arbitrary pair of points on a geodesic triangle $\Delta$ does not exceed the distance between its pair of corresponding points on its comparison triangle $\bar{\Delta}$. If $\Delta$ is a geodesic triangle and $\bar{\Delta}$ is its comparison triangle in $X$, then $\Delta$ is said to satisfy the $\operatorname{CAT}(0)$ inequality for all points $x, y$ of $\Delta$ and $\bar{x}, \bar{y}$ of $\bar{\Delta}$, if

$$
d(x, y)=d_{\mathbb{R}^{2}}(\bar{x}, \bar{y})
$$

Let $x, y, z$ be points in $X$ and $y_{0}$ be the midpoint of the segment $[y, z]$; then the $\operatorname{CAT}(0)$ inequality implies

$$
d^{2}\left(x, y_{0}\right) \leq \frac{1}{2} d^{2}(x, y)+\frac{1}{2} d^{2}(x, z)-\frac{1}{4} d(y, z)
$$

Inequality (8) is known as $\mathrm{CN}$ inequality of Bruhat and Tits [33]. A geodesic space $X$ is said to be a CAT(0) space if all geodesic triangles satisfy the $\mathrm{CN}$ inequality. Equivalently, $X$ is called a $\mathrm{CAT}(0)$ space if and only if it satisfies the $\mathrm{CN}$ inequality. Examples of CAT(0) spaces includes Hadamard manifold, $\mathbb{R}$-trees [34], pre-Hilbert spaces [35], hyperbolic metric [36] and Hilbert balls [37].

Let $D$ be a nonempty subset of a metric space $(X, d)$. A point $x \in X$ is called a fixed point of a nonlinear mapping $T: D \rightarrow X$, if $x=T x$. We denote by $F(T)$ the set of fixed points of $T$. The mapping $T$ is said to be:

1. $\quad L$-Lipschitz, if there exists $L>0$ such that

$$
d(T x, T y) \leq L d(x, y), \forall x, y \in X
$$

if $L=1$, then $T$ is called nonexpansive;

2. Firmly nonexpansive (see [38]), if

$$
d^{2}(T x, T y) \leq\langle\overrightarrow{T x T y}, \overrightarrow{x y}\rangle \forall x, y \in X ;
$$

3. Quasi-nonexpansive, if $F(T) \neq \varnothing$ and

$$
d(T x, p) \leq d(x, p) \forall x \in X \text { and } p \in F(T) ;
$$

4. $k$-demicontractive, if $F(T) \neq \varnothing$ and there exists $k \in[0,1)$ such that

$$
d^{2}(T x, p) \leq d^{2}(x, p)+k d^{2}(x, T x) \forall x, y \in X, \text { and } p \in F(T) .
$$

Obviously, the class of quasi-nonexpansive are $k$-demicontractive mappings. However, the converse is not true (see [39] Example 1.1). 
Definition 1. [40] Let a pair $(a, b) \in X \times X$, denoted by $\overrightarrow{a b}$, be called a vector in $X \times X$. The quasilinearization map $\langle.,\rangle:.(X \times X) \times(X \times X) \rightarrow \mathbb{R}$ is defined by

$$
\langle\overrightarrow{a b}, \overrightarrow{c d}\rangle=\frac{1}{2}\left(d^{2}(a, d)+d^{2}(b, c)-d^{2}(a, c)-d^{2}(b, d)\right), \forall a, b, c, d \in X .
$$

It is easy to see that $\langle\overrightarrow{b a}, \overrightarrow{c d}\rangle=-\langle\overrightarrow{a b}, \overrightarrow{c d}\rangle,\langle\overrightarrow{a b}, \overrightarrow{c d}\rangle=\langle\overrightarrow{a c}, \overrightarrow{c d}\rangle+\langle\overrightarrow{e b}, \overrightarrow{c d}\rangle$ and $\langle\overrightarrow{a b}, \overrightarrow{c d}\rangle=\langle\overrightarrow{c d}, \overrightarrow{a b}\rangle$ for all $a, b, c, d, e \in X$. Furthermore, a geodesic space $X$ is said to satisfy the Cauchy-Schwarz inequality if

$$
\langle\overrightarrow{a b}, \overrightarrow{c d}\rangle \leq d(a, b) d(c, d), \forall a, b, c, d \in X
$$

It is known from [41] that a geodesically connected metric space is a CAT(0) space if and only if it satisfies the Cauchy-Schwarz inequality.

We state some known and useful results which will be needed in the proof of our main results. In the sequel, we denote strong and $\Delta$-convergence by " $\rightarrow$ " and " $\rightarrow$ " respectively.

Let $\left\{x_{n}\right\}$ be a bounded sequence in $X$ and $r\left(.,\left\{x_{n}\right\}\right): X \rightarrow[0, \infty)$ be a continuous mapping defined by $r\left(x,\left\{x_{n}\right\}\right)=\limsup _{n \rightarrow \infty} d\left(x, x_{n}\right)$. The asymptotic radius of $\left\{x_{n}\right\}$ is given by $r\left(\left\{x_{n}\right\}\right):=\inf \left\{r\left(x,\left\{x_{n}\right\}\right):\right.$ $x \in X\}$ while the asymptotic center of $\left\{x_{n}\right\}$ is the set $A\left(\left\{x_{n}\right\}\right)=\left\{x \in X: r\left(x,\left\{x_{n}\right\}\right)=r\left(\left\{x_{n}\right\}\right)\right\}$. It is known that in an Hadamard space $X, A\left(\left\{x_{n}\right\}\right)$ consists of exactly one point. A sequence $\left\{x_{n}\right\}$ in $X$ is said to be $\Delta$-convergent to a point $x \in X$, if $A\left(\left\{x_{n_{k}}\right\}\right)=\{x\}$ for every subsequence $\left\{x_{n_{k}}\right\}$ of $\left\{x_{n}\right\}$. In this case, we write $\Delta-\lim _{n \rightarrow \infty} x_{n}=x$ (see $[42,43]$ ).

Definition 2. Let $D$ be a nonempty, closed and convex subset of an Hadamard space X. The metric projection is a mapping $P_{D}: X \rightarrow D$ which assigns to each $x \in X$, the unique point $P_{D} x \in D$ such that

$$
d\left(x, P_{D} x\right)=\inf \{d(x, y): y \in D\}
$$

Lemma 1. [44] Let $D$ be a nonempty, closed convex subset of an Hadamard space $X, x \in X$ and $u \in D$. Then $u=P_{D} x$ if and only if $\langle\overrightarrow{x u}, \overrightarrow{u y}\rangle \geq 0$, for all $y \in D$.

Lemma 2. [29] Let $D$ be a nonempty convex subset of an Hadamard space $X$ and $T: D \rightarrow X$ be an $\alpha$-inverse strongly monotone mapping. Assume $\lambda \in[0,1]$ and define $T_{\lambda}: D \rightarrow X$ by $T_{\lambda} x=(1-\lambda) x \oplus \lambda T x$. If $0<\lambda<2 \alpha$, then $T_{\lambda}$ is nonexpansive and $F\left(T_{\lambda}\right)=F(T)$.

Lemma 3. [29] Let $D$ be a nonempty convex subset of an Hadamard space $X$ and $T: D \rightarrow X$ be a mapping. Then

$$
V I(D, T)=V I\left(D, T_{\lambda}\right)
$$

where $\lambda \in(0,1]$ and $T_{\lambda}: D \rightarrow X$ is a mapping defined by $T_{\lambda} x=(1-\lambda) x \oplus \lambda T x$, for all $x \in D$.

Remark 1. Observe from Lemma 2 that

$$
F\left(P_{D} T\right)=V I(D, T)=V I\left(D, T_{\lambda}\right)=F\left(P_{D} T_{\lambda}\right)
$$

Lemma 4. [29] Let $D$ be a nonempty bounded closed convex subset of an Hadamard space $X$ and $T: D \rightarrow X$ be an $\alpha$-inverse-strongly monotone mapping. Then $\operatorname{VI}(D, T)$ is nonempty, closed and convex.

Lemma 5. [41,45] Let $X$ be an Hadamard space. Then for all $x, y, z \in X$ and all $t, s \in[0,1]$, we have

(i) $\quad d(t x \oplus(1-t) y, z) \leq t d(x, z)+(1-t) d(y, z)$,

(ii) $d^{2}(t x \oplus(1-t) y, z) \leq t d^{2}(x, z)+(1-t) d^{2}(y, z)-t(1-t) d^{2}(x, y)$,

(iii) $d^{2}(z, t x \oplus(1-t) y) \leq t^{2} d^{2}(z, x)+(1-t)^{2} d^{2}(z, y)+2 t(1-t)\langle\overrightarrow{z x}, \overrightarrow{z y}\rangle$. 
Lemma 6. [46] Let $X$ be a $C A T(0)$ space and $z \in X$. Let $x_{1}, \cdots, x_{N} \in X$ and $\gamma_{1}, \cdots, \gamma_{N}$ be real numbers in $[0,1]$ such that $\sum_{i=1}^{N} \gamma_{i}=1$. Then the following inequality holds:

$$
d^{2}\left(\sum_{i=1}^{N} \oplus \gamma_{i} x_{i}, z\right) \leq \sum_{i=1}^{N} \gamma_{i} d^{2}\left(x_{i}, z\right)-\sum_{i, j=1, i \neq j}^{N} \gamma_{i} \gamma_{j} d^{2}\left(x_{i}, x_{j}\right)
$$

Lemma 7. [47] Every bounded sequence in an Hadamard space has a $\Delta$-convergent subsequence.

Lemma 8. [48] Let $X$ be an Hadamard space, $\left\{x_{n}\right\}$ be a sequence in $X$ and $x \in X$. Then $\left\{x_{n}\right\} \Delta$-converges to $x$ if and only if

$$
\limsup _{n \rightarrow \infty}\left\langle\overrightarrow{x_{n} x}, \overrightarrow{y x}\right\rangle \leq 0, \forall y \in X
$$

Definition 3. Let $D$ be a nonempty, closed and convex subset of an Hadamard space X. A mapping $T$ : $D \rightarrow D$ is said to be $\Delta$-demiclosed, if for any bounded sequence $\left\{x_{n}\right\}$ in $X$, such that $\Delta-\lim _{n \rightarrow \infty} x_{n}=x$ and $\lim _{n \rightarrow \infty} d\left(x_{n}, T x_{n}\right)=0$, then $x=T x$.

Lemma 9. [49] Let $X$ be an Hadamard space and $T: X \rightarrow X$ be a nonexpansive mapping. Then $T$ is $\Delta$-demiclosed.

Lemma 10. $[50,51]$ Let $\left\{a_{n}\right\}$ be a sequence of non-negative real numbers satisfying

$$
a_{n+1} \leq\left(1-\alpha_{n}\right) a_{n}+\delta_{n}, n \geq 0,
$$

where $\left\{\alpha_{n}\right\}$ and $\left\{\delta_{n}\right\}$ satisfy the following conditions:

(i) $\left\{\alpha_{n}\right\} \subset[0,1], \sum_{n=0}^{\infty} \alpha_{n}=\infty$,

(ii) $\quad \limsup _{n \rightarrow \infty} \frac{\delta_{n}}{\alpha_{n}} \leq 0$ or $\sum_{n=0}^{\infty}\left|\delta_{n}\right| \leq \infty$.

Then $\lim _{n \rightarrow \infty} a_{n}=0$.

Lemma 11. [52] Let $\left\{a_{n}\right\}$ be a sequence of non-negative real numbers such that there exists a subsequence $\left\{n_{j}\right\}$ of $\{n\}$ with $a_{n_{j}}<a_{n_{j}+1}$ for all $j \in \mathbb{N}$. Then there exists a nondecreasing sequence $\left\{m_{k}\right\} \subset \mathbb{N}$ such that $m_{k} \rightarrow \infty$ and the following properties are satisfied by all (sufficiently large) numbers $k \in \mathbb{N}$ :

$$
a_{m_{k}} \leq a_{m_{k}+1} \text { and } a_{k} \leq a_{m_{k}+1} .
$$

In fact, $m_{k}=\max \left\{i \leq k: a_{i}<a_{i+1}\right\}$.

\section{Main Results}

In this section, we present our strong convergence results.

Theorem 1. Let $X$ be an Hadamard space and $D$ be a nonempty, closed and convex subset of $X$. Let $S_{i}$ : $D \rightarrow D$ be a finite family of $L_{i}$-Lipschitz $k_{i}$-demicontractive mappings and $\Delta$-demiclosed such that $L>$ $0, L=\max \left\{L_{i}, i=1,2, \cdots, N\right\}, k \in[0,1), k=\max \left\{k_{i}, i=1,2, \cdots, N\right\}, k_{i} \in[0,1), i=1,2, \cdots, N$. Let $T_{i}: D \rightarrow X$ be a finite family of $\alpha_{i}$-inverse strongly monotone mappings and $f$ be a contraction on $D$ with coefficient $\theta \in(0,1)$. Suppose that $\Gamma:=\cap_{i=1}^{N} V I\left(D, T_{i}\right) \cap \cap_{i=1}^{N} F\left(S_{i}\right) \neq \varnothing$. For arbitrary $x_{1} \in D$, let the sequence $\left\{x_{n}\right\}$ be generated by 


$$
\left\{\begin{array}{l}
w_{n}=\gamma_{n} f\left(x_{n}\right) \oplus\left(1-\gamma_{n}\right) x_{n}, \\
y_{n}=\beta_{n, 0} w_{n} \oplus \sum_{i=1}^{N} \oplus \beta_{n, i} P_{D} T_{\lambda_{i}} w_{n}, \\
x_{n+1}=\alpha_{n, 0} y_{n} \oplus \sum_{i=1}^{N} \oplus \alpha_{n, i} S_{i} y_{n}, \quad \forall n \geq 1,
\end{array}\right.
$$

where $T_{\lambda_{i}}=\left(1-\lambda_{i}\right) x \oplus \lambda_{i} T_{i} x, 0<\lambda_{i}<2 \alpha_{i}$, for each $i=1,2, \cdots, N,\left\{\gamma_{n}\right\},\left\{\beta_{n, i}\right\}$ and $\left\{\alpha_{n, i}\right\} \in(0,1)$ such that the following conditions are satisfied:

(A1) $\lim _{\substack{n \rightarrow \infty \\ \infty}} \gamma_{n}=0$;

(A2) $\sum_{n=1}^{\infty} \gamma_{n}=\infty$,

(A3) $0<a \leq \beta_{n, i}, \alpha_{n, i} \leq b<1 ; \sum_{i=0}^{N} \alpha_{n, i}=1$ and $\sum_{i=0}^{N} \beta_{n, i}=1$;

(A4) $0<c \leq \alpha_{n, 0}-k \leq d<1$.

Then, the sequence $\left\{x_{n}\right\}$ converges strongly to an element $\bar{z}=P_{\Gamma} f(\bar{z})$, where $P_{\Gamma}$ is the metric projection of $X$ onto $\Gamma$.

Proof. Let $p \in \Gamma$; then by (10), condition (A3), Lemma 6 and the fact that $P_{D} T_{\lambda}$ is nonexpansive, we have

$$
\begin{aligned}
d^{2}\left(y_{n}, p\right) & =d^{2}\left(\beta_{n, 0} w_{n} \sum_{i=1}^{N} \oplus \beta_{n, i} P_{D} T_{\lambda_{i}} w_{n}, p\right) \\
& \leq \beta_{n, 0} d^{2}\left(w_{n}, p\right)+\sum_{i=1}^{N} \beta_{n, i} d^{2}\left(P_{D} T_{\lambda_{i}} w_{n}, p\right)-\sum_{i=1}^{N} \beta_{n, 0} \beta_{n, i} d^{2}\left(P_{D} T_{\lambda_{i}} w_{n}, w_{n}\right) \\
& \leq d^{2}\left(w_{n}, p\right)-\sum_{i=1}^{N} \beta_{n, 0} \beta_{n, i} d^{2}\left(P_{D} T_{\lambda_{i}} w_{n}, w_{n}\right)
\end{aligned}
$$

Additionally, since $S_{i}$ is demicontractive, we have from (10) and Lemma 6 that

$$
\begin{aligned}
d^{2}\left(x_{n+1}, p\right) & \leq \alpha_{n, 0} d^{2}\left(y_{n}, p\right)+\sum_{i=1}^{N} \alpha_{n, i} d^{2}\left(S_{i} y_{n}, p\right)-\sum_{i=1}^{N} \alpha_{n, 0} \alpha_{n, i} d^{2}\left(y_{n}, S_{i} y_{n}\right) \\
& \leq \alpha_{n, 0} d^{2}\left(y_{n}, p\right)+\sum_{i=1}^{N} \alpha_{n, i}\left[d^{2}\left(y_{n}, p\right)+k d^{2}\left(S_{i} y_{n}, y_{n}\right)\right]-\sum_{i=1}^{N} \alpha_{n, 0} \alpha_{n, i} d^{2}\left(y_{n}, S_{i} y_{n}\right) \\
& =d^{2}\left(y_{n}, p\right)-\sum_{i=1}^{N} \alpha_{n, i}\left(\alpha_{n, 0}-k\right) d^{2}\left(y_{n}, S_{i} y_{n}\right) .
\end{aligned}
$$

From (11), (12) and condition (A4), we have

$$
\begin{aligned}
d\left(x_{n+1}, p\right) & \leq \gamma_{n} d\left(f\left(x_{n}\right), p\right)+\left(1-\gamma_{n}\right) d\left(x_{n}, p\right) \\
& \leq \gamma_{n} \theta d\left(x_{n}, p\right)+\gamma_{n} d(f(p), p)+\left(1-\gamma_{n}\right) d\left(x_{n}, p\right) \\
& \leq\left(1-\gamma_{n}(1-\theta)\right) d\left(x_{n}, p\right)+\gamma_{n} d(f(p), p) . \\
& \leq \max \left\{d\left(x_{n}, p\right), \frac{1}{1-\theta} d(f(p), p)\right\} \\
& \vdots \\
& \leq \max \left\{d\left(x_{1}, p\right), \frac{1}{1-\theta} d(f(p), p)\right\} .
\end{aligned}
$$

Thus, $\left\{x_{n}\right\}$ is bounded. Consequently, $\left\{w_{n}\right\},\left\{y_{n}\right\},\left\{S y_{n}\right\}$ and $\left\{P_{D} T_{\lambda_{i}} w_{n}\right\}$ are also bounded. Now we divide the rest of the proof into two cases: 
Case 1: Assume that $\left\{d^{2}\left(x_{n}, p\right)\right\}$ is a monotonically non-increasing sequence. Then, $\left\{d^{2}\left(x_{n}, p\right)\right\}$ is convergent and

$$
d^{2}\left(x_{n}, p\right)-d^{2}\left(x_{n+1}, p\right) \rightarrow 0, \text { as } n \rightarrow \infty .
$$

Hence, from (11) and (12), we have

$$
\begin{aligned}
d^{2}\left(x_{n+1}, p\right) & \leq d^{2}\left(w_{n}, p\right)-\sum_{i=1}^{N} \beta_{n, 0} \beta_{n, i} d^{2}\left(P_{D} T_{\lambda_{i}} w_{n}, w_{n}\right)-\sum_{i=1}^{N} \alpha_{n, i}\left(\alpha_{n, 0}-k\right) d^{2}\left(y_{n}, S_{i} y_{n}\right) \\
& \leq \gamma_{n} d^{2}\left(f\left(x_{n}\right), p\right)+\left(1-\gamma_{n}\right) d^{2}\left(x_{n}, p\right)-\sum_{i=1}^{N} \beta_{n, 0} \beta_{n, i} d^{2}\left(P_{D} T_{\lambda_{i}} w_{n}, w_{n}\right)-\sum_{i=1}^{N} \alpha_{n, i}\left(\alpha_{n, 0}-k\right) d^{2}\left(y_{n}, S_{i} y_{n}\right)
\end{aligned}
$$

which implies

$$
\sum_{i=1}^{N} \beta_{n, 0} \beta_{n, i} d^{2}\left(P_{D} T_{\lambda_{i}} w_{n}, w_{n}\right) \leq \gamma_{n}\left(d^{2}\left(f\left(x_{n}\right), p\right)-d^{2}\left(x_{n}, p\right)\right)+d^{2}\left(x_{n}, p\right)-d^{2}\left(x_{n+1}, p\right) .
$$

By conditions (A1) and (A3), we obtain that

$$
\lim _{n \rightarrow \infty} d\left(P_{D} T_{\lambda_{i}} w_{n}, w_{n}\right)=0, i=0,1,2, \cdots, N
$$

Similarly, from (13) and condition (A1), we have

$$
\lim _{n \rightarrow \infty} d\left(S_{i} y_{n}, y_{n}\right)=0, i=0,1,2, \cdots, N \text {. }
$$

Additionally,

$$
d\left(w_{n}, x_{n}\right) \leq \gamma_{n} d\left(f\left(x_{n}\right), x_{n}\right) \rightarrow 0 \text { as } n \rightarrow \infty
$$

Again from (10) and Lemma 6, we have

$$
\begin{aligned}
d^{2}\left(y_{n}, x_{n}\right) & \leq \beta_{n, 0} d^{2}\left(w_{n}, x_{n}\right)+\sum_{i=1}^{N} \beta_{n, i} d^{2}\left(P_{D} T_{\lambda_{i}} w_{n}, x_{n}\right) \\
& \leq \beta_{n, 0} d^{2}\left(w_{n}, x_{n}\right)+\sum_{i=1}^{N} \beta_{n, i}\left[d\left(P_{D} T_{\lambda_{i}} w_{n}, w_{n}\right)+d\left(w_{n}, x_{n}\right)\right]^{2}
\end{aligned}
$$

Hence, from (14) and (16), we obtain

$$
d\left(y_{n}, x_{n}\right) \rightarrow 0 \text { as } n \rightarrow \infty .
$$

Additionally, from (15) and (17), we have

$$
d\left(S_{i} y_{n}, x_{n}\right) \leq d\left(S_{i} y_{n}, y_{n}\right)+d\left(y_{n}, x_{n}\right) \rightarrow 0, \text { as } n \rightarrow \infty, i=0,1,2, \cdots, N .
$$

Since $S_{i}$ is Lipschitz, then from (17) and (18), we have that

$$
\begin{aligned}
d\left(S_{i} x_{n}, x_{n}\right) & \leq d\left(S_{i} x_{n}, S_{i} y_{n}\right)+d\left(S_{i} y_{n}, x_{n}\right) \\
& \leq L d\left(x_{n}, y_{n}\right)+d\left(S_{i} y_{n}, x_{n}\right) \rightarrow 0, \text { as } n \rightarrow \infty, i=0,1,2, \cdots, N .
\end{aligned}
$$

Hence, from (14), (16) and Lemma 2, we obtain that

$$
\begin{aligned}
d\left(P_{D} T_{\lambda_{i}} x_{n}, x_{n}\right) & \leq d\left(P_{D} T_{\lambda_{i}} x_{n}, P_{D} T_{\lambda_{i}} w_{n}\right)+d\left(P_{D} T_{\lambda_{i}} w_{n}, w_{n}\right)+d\left(w_{n}, x_{n}\right) \\
& \leq d\left(x_{n}, w_{n}\right)+d\left(P_{D} T_{\lambda_{i}} w_{n}, w_{n}\right)+d\left(w_{n}, x_{n}\right) \rightarrow 0, \text { as } n \rightarrow \infty, i=0,1,2, \cdots, N
\end{aligned}
$$


Since $\left\{x_{n}\right\}$ is bounded, by Lemma 7 there exists a subsequence $\left\{x_{n_{k}}\right\}$ of $\left\{x_{n}\right\}$ such that $\Delta-$ $\lim _{k \rightarrow \infty} x_{n_{k}}=z$ for some $z \in D$. Then, it follows from (16) that there exists a subsequence $\left\{w_{n_{k}}\right\}$ of $\left\{w_{n}\right\}$, such that $\Delta-\lim _{k \rightarrow \infty} w_{n_{k}}=z$. Additionally, from (17), we have that $\Delta-\lim _{k \rightarrow \infty} y_{n_{k}}=z$. Since $S_{i}$ is $\Delta$-demiclosed for each $i=1,2, \cdots, N$, it follows from (19) that $z \in \cap_{i=0}^{N} F\left(S_{i}\right)$. Additionally, $P_{D} T_{\lambda_{i}}$ is nonexpansive (by Lemma 2) for each $i=1,2, \cdots, N$, thus we obtain from (20) and Remark 1 that $z \in \cap_{i=0}^{N} F\left(P_{D} T_{\lambda_{i}}\right)=\cap_{i=0}^{N} F\left(P_{D} T_{i}\right)$. Hence, $z \in \Gamma$.

Next we show that $\left\{x_{n}\right\}$ converges strongly to $\bar{z}=P_{\Gamma} f(\bar{z})$. Since $\left\{x_{n}\right\}$ is bounded, we may choose without loss of generality, a subsequence $\left\{x_{n_{k}}\right\}$ of $\left\{x_{n}\right\}$ such that $\left\{x_{n_{k}}\right\} \Delta$-converges to $z$ and

$$
\limsup _{n \rightarrow \infty}\left\langle\overrightarrow{f(\vec{z}) \vec{z}}, \overrightarrow{x_{n}} \vec{z}\right\rangle=\lim _{k \rightarrow \infty}\left\langle\overrightarrow{f(\vec{z}) \vec{z}}, \overrightarrow{x_{n_{k}}} \vec{z}\right\rangle
$$

Thus, by (21) and Lemma 1, we obtain that

$$
\limsup _{k \rightarrow \infty}\left\langle\overrightarrow{f(\vec{z}) \vec{z}}, \overrightarrow{x_{n} \vec{z}}\right\rangle=\langle\overrightarrow{f(\vec{z})} \vec{z}, \vec{z} \vec{z}\rangle \leq 0
$$

From (12), Lemma 5 (iii) and quasilinearization properties in Definition 1, we have that

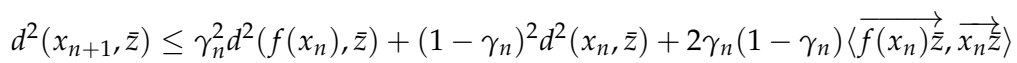

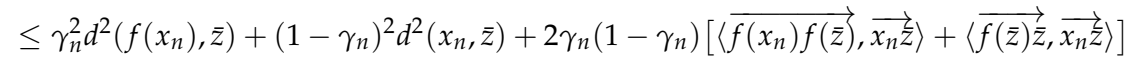

$$
\begin{aligned}
& \leq \gamma_{n}^{2} d^{2}\left(f\left(x_{n}\right), \bar{z}\right)+\left(1-\gamma_{n}\right)^{2} d^{2}\left(x_{n}, \bar{z}\right)+2 \gamma_{n}\left(1-\gamma_{n}\right)\left[\theta d^{2}\left(x_{n}, \bar{z}\right)+\left\langle\overrightarrow{f(\bar{z}) \bar{z}}, \overrightarrow{x_{n}} \bar{z}\right\rangle\right] \\
& \leq\left(1-2 \gamma_{n}+2 \gamma_{n} \theta\right) d^{2}\left(x_{n}, \bar{z}\right)+2 \gamma_{n}\left(1-\gamma_{n}\right)\left\langle\overrightarrow{f(\vec{z}) \bar{z}}, \overrightarrow{x_{n}} \vec{z}\right\rangle+\gamma_{n}^{2}\left(d^{2}\left(f\left(x_{n}\right), \bar{z}\right)+d^{2}\left(x_{n}, \bar{z}\right)\right) \\
& =1-2 \gamma_{n}(1-\theta) d^{2}\left(x_{n}, \bar{z}\right)+2 \gamma_{n}(1-\theta)\left[\frac{1-\gamma_{n}}{1-\theta}\left\langle\overrightarrow{f(\vec{z}) \vec{z},} \overrightarrow{x_{n}} \vec{z}\right\rangle+\frac{\gamma_{n}}{2(1-\theta)}\left(d^{2}\left(f\left(x_{n}\right), \bar{z}\right)+d^{2}\left(x_{n}, \bar{z}\right)\right)\right] .
\end{aligned}
$$

That is,

$$
d^{2}\left(x_{n+1}, \bar{z}\right) \leq 1-2 \gamma_{n}(1-\theta) d^{2}\left(x_{n}, \bar{z}\right)+2 \gamma_{n}(1-\theta) M_{n}
$$

where

$$
M_{n}=\left[\frac{1-\gamma_{n}}{1-\theta}\left\langle\overrightarrow{f(\bar{z}) \bar{z}}, \overrightarrow{x_{n}} \vec{z}\right\rangle+\frac{\gamma_{n}}{2(1-\theta)}\left(d^{2}\left(f\left(x_{n}\right), \bar{z}\right)+d^{2}\left(x_{n}, \bar{z}\right)\right)\right] .
$$

Thus from (22), (23) and condition (A1), we conclude by Lemma 10 that $\left\{x_{n}\right\}$ converges strongly to $\bar{z}=P_{\Gamma} f(\bar{z})$.

Case 2: Suppose there exists a subsequence $\left\{n_{k}\right\}$ of $\{n\}$ such that $d^{2}\left(x_{n_{k}}, p\right) \leq d^{2}\left(x_{k+1}, p\right)$ for all $k \in \mathbb{N}$. Then by Lemma 11, there exists a nondecreasing sequence $\left\{m_{k}\right\} \subset \mathbb{N}$ such that $m_{k} \rightarrow \infty$ :

$$
d\left(x_{m_{k}}, p\right)<d\left(x_{m_{k+1}}, p\right) \text {, and } d\left(x_{k}, p\right)<d\left(x_{k+1}, p\right) \forall k \in \mathbb{N} .
$$

Therefore

$$
\begin{aligned}
0 & \leq \lim _{k \rightarrow \infty}\left(d\left(x_{m_{k+1}}, p\right)-d\left(x_{m_{k}}, p\right)\right) \\
& \leq \limsup _{n \rightarrow \infty}\left(d\left(x_{n+1}, p\right)-d\left(x_{n}, p\right)\right) \\
& \leq \limsup _{n \rightarrow \infty}\left(\gamma_{n} d\left(f\left(x_{n}\right), p\right)+\left(1-\gamma_{n}\right) d\left(x_{n}, p\right)-d\left(x_{n}, p\right)\right) \\
& =\limsup _{n \rightarrow \infty}\left(\gamma_{n}\left(d\left(f\left(x_{n}\right), p\right)-d\left(x_{n}, p\right)\right)\right)=0 .
\end{aligned}
$$


This implies that

$$
\lim _{k \rightarrow \infty}\left(d\left(x_{m_{k+1}}, p\right)-d\left(x_{m_{k}}, p\right)\right)=0
$$

Following the arguments as in Case 1, we get

$$
\lim _{k \rightarrow \infty}\left\langle\overrightarrow{f(\bar{z}) \bar{z}}, \overrightarrow{x_{m_{k}}} \vec{z}\right\rangle \leq 0
$$

Hence, from (23), we obtain that

$$
d^{2}\left(x_{m_{k+1}}, \bar{z}\right) \leq 1-2 \gamma_{m_{k}}(1-\theta) d^{2}\left(x_{m_{k}}, \bar{z}\right)+2 \gamma_{m_{k}}(1-\theta) M_{m_{k}} .
$$

Additionally, from (24), we have that

$$
d^{2}\left(x_{m_{k}}, \bar{z}\right) \leq M_{m_{k}}
$$

which implies that

$$
\lim _{k \rightarrow \infty} d^{2}\left(x_{m_{k}}, \bar{z}\right)=0
$$

Thus, from cases 1 and 2 , we conclude that $\left\{x_{n}\right\}$ converges to $\bar{z}=P_{\Gamma} f(\bar{z})$ which is an element of $\Gamma$.

We present some consequences of our main results.

Now, by setting $S_{i}$ to be a family of quasi-nonexpansive mappings in Theorem 1, we obtain the following result:

Corollary 2. Let $X$ be an Hadamard space and $D$ be a nonempty, closed and convex subset of $X$. Let $S_{i}: D \rightarrow D$ be a finite family of quasi-nonexpansive mappings, $T_{i}: D \rightarrow X$ be a finite family of $\alpha_{i}$-inverse strongly monotone mappings and $f$ be a contraction on $D$ with coefficient $\theta \in(0,1)$. Suppose that $\Gamma:=\cap_{i=1}^{N} V I\left(D, T_{i}\right) \cap$ $\cap_{i=1}^{N} F\left(S_{i}\right) \neq \varnothing$. For arbitrary $x_{1}, \in D$, let the sequence $\left\{x_{n}\right\}$ be generated by

$$
\left\{\begin{array}{l}
w_{n}=\gamma_{n} f\left(x_{n}\right) \oplus\left(1-\gamma_{n}\right) x_{n} \\
y_{n}=\beta_{n, 0} w_{n} \oplus \sum_{i=1}^{N} \oplus \beta_{n, i} P_{D} T_{\lambda_{i}} w_{n} \\
x_{n+1}=\alpha_{n, 0} y_{n} \oplus \sum_{i=1}^{N} \oplus \alpha_{n, i} S_{i} y_{n}, \quad \forall n \geq 1
\end{array}\right.
$$

where $T_{\lambda_{i}}=\left(1-\lambda_{i}\right) x \oplus \lambda_{i} T_{i} x, 0<\lambda_{i}<2 \alpha_{i}$, for each $i=1,2, \cdots, N,\left\{\gamma_{n}\right\},\left\{\beta_{n_{i}}\right\}$ and $\left\{\alpha_{n_{i}}\right\} \in(0,1)$ such that conditions (A1)-(A3) of Theorem 1 are satisfied. Then, the sequence $\left\{x_{n}\right\}$ converges strongly to an element $\bar{z}=P_{\Gamma} f(\bar{z})$, where $P_{\Gamma}$ is the metric projection of $X$ onto $\Gamma$.

Proof. The proof follows from the proof of Theorem 1.

By setting $N=1$ in Corollary 2, we obtain the following result:

Corollary 3. Let $X$ be an Hadamard space and $D$ be a nonempty, closed and convex subset of X. Let $S: D \rightarrow D$ be a quasi-nonexpansive mapping, $T: D \rightarrow X$ be an $\alpha$-inverse strongly monotone mapping and $f$ be a 
contraction on $D$ with coefficient $\theta \in(0,1)$. Suppose that $\Gamma:=V I(D, T) \cap F(S) \neq \varnothing$. For arbitrary $x_{1} \in D$, let the sequence $\left\{x_{n}\right\}$ be generated by

$$
\left\{\begin{array}{l}
w_{n}=\gamma_{n} f\left(x_{n}\right) \oplus\left(1-\gamma_{n}\right) x_{n} \\
y_{n}=\beta_{n, 0} w_{n} \oplus \beta_{n, 1} P_{D} T_{\lambda} w_{n} \\
x_{n+1}=\alpha_{n, 0} y_{n} \oplus \alpha_{n, 1} S y_{n}, \quad \forall n \geq 1
\end{array}\right.
$$

where $T_{\lambda}=(1-\lambda) x \oplus \lambda T x, 0<\lambda<2 \alpha,\left\{\gamma_{n}\right\}$ and $\left\{\alpha_{n}\right\} \in(0,1)$ such that $0<a \leq \beta_{n, i}, \alpha_{n, i} \leq b<$ 1 , for $i=0,1, \sum_{i=0}^{1} \alpha_{n, i}=1, \sum_{i=0}^{1} \beta_{n, i}=1$ and conditions (A1)-(A2) of Theorem 1 are satisfied. Then, the sequence $\left\{x_{n}\right\}$ converges strongly to an element $\bar{z}=P_{\Gamma} f(\bar{z})$, where $P_{\Gamma}$ is the metric projection of $X$ onto $\Gamma$.

Suppose $u=f(x)$ for arbitrary but fixed $u \in X$ and for all $x \in X$ in Theorem 1, we obtain the following result:

Corollary 4. Let $X$ be an Hadamard space and $D$ be a nonempty, closed and convex subset of X. Let $S_{i}$ : $D \rightarrow D$ be a finite family of $L_{i}$-Lipschitz demicontractive mappings and $\Delta$-demiclosed such that $L>0, L=$ $\max \left\{L_{i}, i=1,2, \cdots, N\right\}, k \in[0,1), k=\max \left\{k_{i}, i=1,2, \cdots, N\right\}, k_{i} \in[0,1), i=1,2, \cdots, N$. Let $T_{i}$ : $D \rightarrow X$ be a finite family of $\alpha_{i}$-inverse strongly monotone mappings and suppose that $\Gamma:=\cap_{i=1}^{N} V I\left(D, T_{i}\right) \cap$ $\cap_{i=1}^{N} F\left(S_{i}\right) \neq \varnothing$. For arbitrary $x_{1}, u \in D$, let the sequence $\left\{x_{n}\right\}$ be generated by

$$
\left\{\begin{array}{l}
w_{n}=\gamma_{n} u \oplus\left(1-\gamma_{n}\right) x_{n} \\
y_{n}=\beta_{n, 0} w_{n} \oplus \sum_{i=1}^{N} \oplus \beta_{n, i} P_{D} T_{\lambda_{i}} w_{n} \\
x_{n+1}=\alpha_{n, 0} y_{n} \oplus \sum_{i=1}^{N} \oplus \alpha_{n, i} S_{i} y_{n}, \quad \forall n \geq 1
\end{array}\right.
$$

where $T_{\lambda_{i}}=\left(1-\lambda_{i}\right) x \oplus \lambda_{i} T_{i} x, 0<\lambda_{i}<2 \alpha_{i}$, for each $i=1,2, \cdots, N,\left\{\gamma_{n}\right\},\left\{\beta_{n_{i}}\right\}$ and $\left\{\alpha_{n_{i}}\right\} \in(0,1)$ such that conditions (A1)-(A4) of Theorem 1 are satisfied. Then, the sequence $\left\{x_{n}\right\}$ converges strongly to an element $\bar{z} \in \Gamma$ which is the nearest point to $u$.

By setting $S_{i} \equiv I$ for all $i=1,2, \cdots, N$ in Theorem 1 , we obtain the following result:

Corollary 5. Let $X$ be an Hadamard space and $D$ be a nonempty, closed and convex subset of $X$. Let $T_{i}: D \rightarrow X$ be a finite family of $\alpha_{i}$-inverse strongly monotone mappings and $f$ be a contraction on $D$ with coefficient $\theta \in(0,1)$. Suppose that $\Gamma:=\cap_{i=1}^{N} V I\left(D, T_{i}\right) \neq \varnothing$. For arbitrary $x_{1} \in D$, let the sequence $\left\{x_{n}\right\}$ be generated by

$$
\left\{\begin{array}{l}
w_{n}=\gamma_{n} f\left(x_{n}\right) \oplus\left(1-\gamma_{n}\right) x_{n} \\
y_{n}=\beta_{n, 0} w_{n} \oplus \sum_{i=1}^{N} \oplus \beta_{n, i} P_{D} T_{\lambda_{i}} w_{n} \\
x_{n+1}=\alpha_{n, 0} y_{n} \oplus \sum_{i=i}^{N} \oplus \alpha_{n, i} y_{n} \forall n \geq 1,
\end{array}\right.
$$

where $T_{\lambda_{i}}=\left(1-\lambda_{i}\right) x \oplus \lambda_{i} T_{i} x, 0<\lambda_{i}<2 \alpha_{i}$, for each $i=1,2, \cdots, N,\left\{\gamma_{n}\right\},\left\{\beta_{n_{i}}\right\}$ and $\left\{\alpha_{n_{i}}\right\} \in(0,1)$ such that conditions (A1)-(A3) of Theorem 1 are satisfied. Then, the sequence $\left\{x_{n}\right\}$ converges strongly to an element $\bar{z}=P_{\Gamma} f(\bar{z})$, where $P_{\Gamma}$ is the metric projection of $X$ onto $\Gamma$.

\section{Numerical Example}

In this section, we give a numerical experiment to show the applicability of our result. 
Example 1. [29] Let $X=\mathbb{R}^{2}$ be an $R$-tree with radial metric $d_{r}$, where $d_{r}(x, y)=d(x, y)$ if $x$ and $y$ are situated on a Euclidean straight line passing through the origin and $d_{r}(x, y)=d(x, \mathbf{0})+d(y, \mathbf{0})$ otherwise. We put $p=(0,1), q=(1,0)$ and $D=A \cup B \cup C$, where

$$
A=\{(0, t): t \in[2 / 3,1]\}, \quad B=\{(t, 0): t \in[2 / 3,1]\}, \quad C=\{(t, s): t+s=1, t \in(0,1)\} .
$$

Define $T: D \rightarrow X$ by

$$
T x=\left\{\begin{array}{l}
q \text { if } x \in A, \\
p \text { if } x \in B \\
x \text { if } x \in C
\end{array}\right.
$$

then $T$ is $\frac{1}{4}$-inverse strongly monotone in $\left(X, d_{r}\right)$.

Now, define $S: D \rightarrow D$ by $S x=\frac{5}{8} x$. We make the following choices of parameters: $\lambda=\frac{1}{4}, \gamma_{n}=\frac{1}{n+1}$, $\alpha_{n, 0}=\frac{2 n}{5 n+7}, \alpha_{n, 1}=\frac{3 n+7}{5 n+7}, \beta_{n, 0}=\frac{n}{3 n+2}, \beta_{n, 1}=\frac{2 n+2}{3 n+2} \forall n \geq 1$ and $f(x)=\frac{1}{2} x \forall x \in X$; then the conditions (A1)-(A3) of Theorem 2 are satisfied. Therefore, for $x_{1} \in X$, Algorithm (28) becomes

$$
\left\{\begin{array}{l}
w_{n}=\frac{1}{n+1} f\left(x_{n}\right) \oplus\left(1-\frac{1}{n+1}\right) x_{n} \\
y_{n}=\beta_{n, 0} w_{n} \oplus \beta_{n, 1} P_{D} T_{\lambda} w_{n} \\
x_{n+1}=\alpha_{n, 0} y_{n} \oplus \alpha_{n, 1} S y_{n} \forall n \geq 1 .
\end{array}\right.
$$

We now consider the following 3 cases for our numerical experiments given in Figure 1 above.

Case 1: $x_{1}=(-0.5,0.5)^{T}$.

Case 2: $x_{1}=(0.5,-0.5)^{T}$.

Case 2: $x_{1}=(1,2)^{T}$.

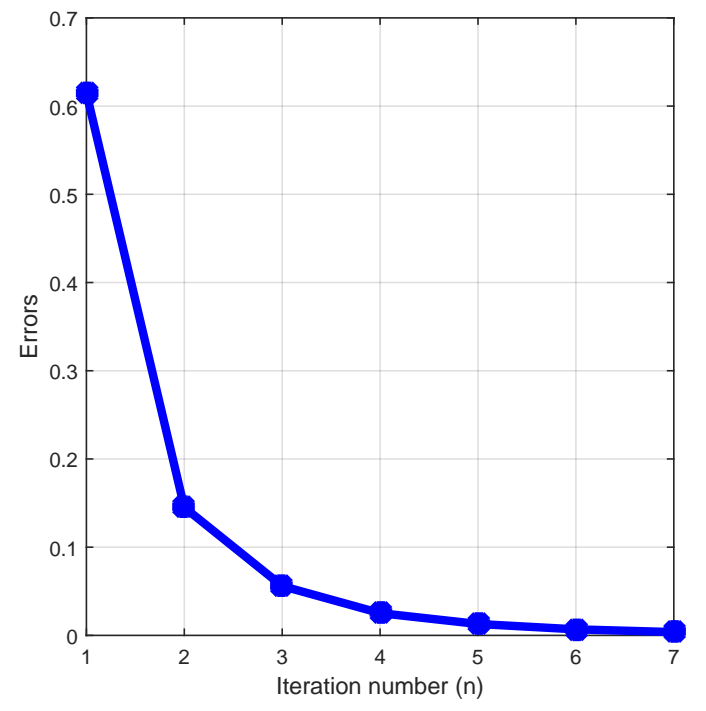

(a)

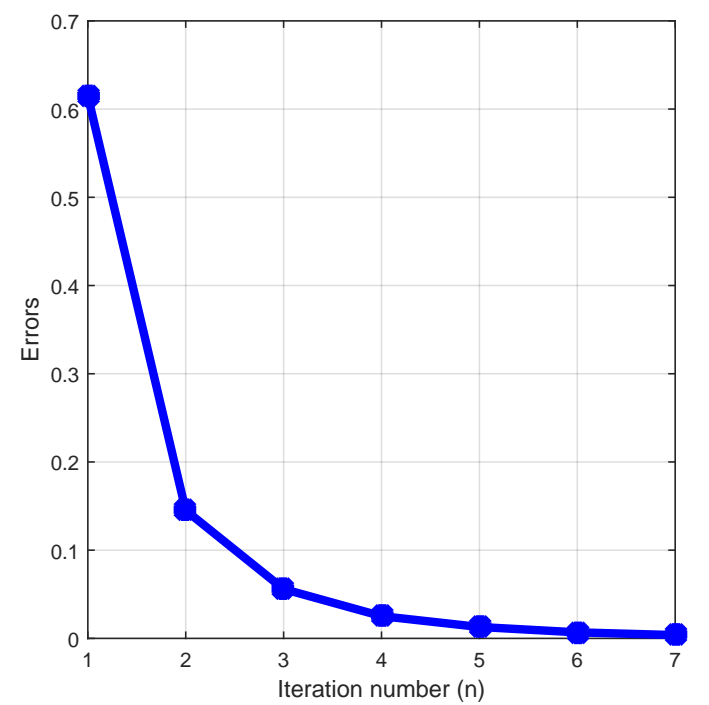

(b)

Figure 1. Cont. 


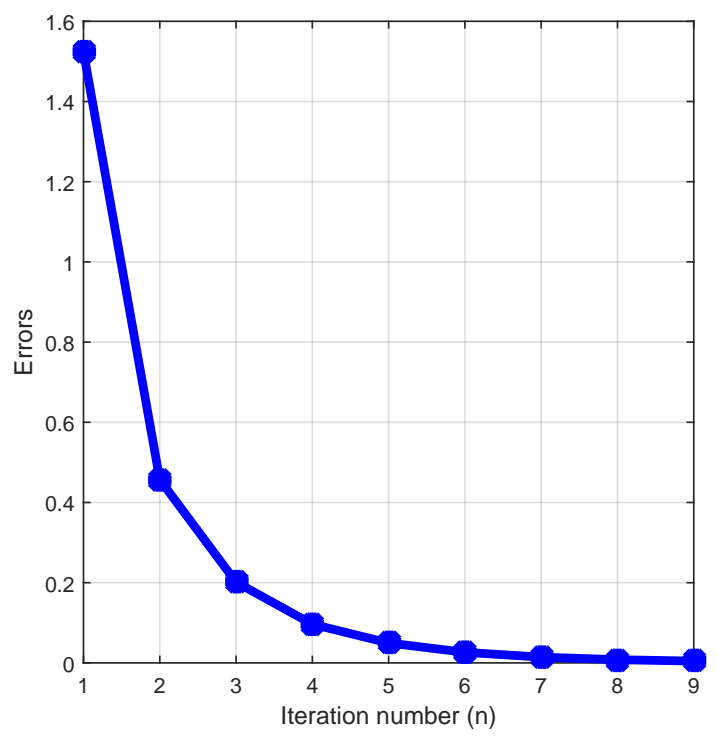

(c)

Figure 1. Errors vs. iteration numbers (n) for Example 1: case 1 (a); case 2 (b); case 3 (c).

Author Contributions: Conceptualization of the article was given by K.O.A., C.I. and O.T.M., methodology by H.A.A., K.O.A., and C.I., software by C.I., validation by O.T.M. and C.I., formal analysis, investigation, data curation, and writing-original draft preparation by K.O.A., H.A.A. and C.I. resources by K.O.A., C.I., H.A.A. and O.T.M. writing-review and editing by K.O.A., C.I. and O.T.M., visualization by C.I. and O.T.M., project administration by O.T.M., Funding acquisition by O.T. All authors have read and agreed to the published version of the manuscript.

Funding: C.I. is funded by National Research Foundation (NRF) South Africa (S\&F-DSI/NRF Free Standing Postdoctoral Fellowship; grant number: 120784); H.A.A. is funded by Department of Science and Technology and National Research Foundation, Republic of South Africa Center of Excellence in Mathematical and Statistical Sciences (DST-NRF COE-MaSS) and O.T.M. is funded by National Research Foundation (NRF) of South Africa Incentive Funding for Rated Researchers (grant number 119903).

Acknowledgments: The authors sincerely thank the anonymous reviewers for their careful reading, constructive comments and fruitful suggestions that substantially improved the manuscript.

Conflicts of Interest: The authors declare no conflict of interest.

\section{References}

1. Oden, J.T.; Kikuchi, N. Theory of variational inequalities with applications to problems of flow through porous media. Int. J. Eng. Sci. 1980, 18, 1173-1284. [CrossRef]

2. Stampacchia, G. Variational inequalities. In Theory and Applicalions of Monotone Operators; Ghizzetti, A., Ed.; Edizioni Oderisi: Gubbio, Italy, 1969; pp. 102-192.

3. Alakoya, T.O.; Jolaoso, L.O.; Mewomo, O.T. Modified inertia subgradient extragradient method with self adaptive stepsize for solving monotone variational inequality and fixed point problems. Optimization 2020. [CrossRef]

4. Alakoya, T.O.; Jolaoso, L.O.; Mewomo, O.T. Two modifications of the inertial Tseng extragradient method with self-adaptive step size for solving monotone variational inequality problems. Demonstr. Math. 2020, 53, 208-224. [CrossRef]

5. Allen, G. Variational inequalities, complementarity problems, and duality theorems. J. Math. Anal. Appl. 1977, 58, 1-10. [CrossRef]

6. Izuchukwu, C.; Mebawondu, A.A.; Mewomo, O.T. A New Method for Solving Split Variational Inequality Problems without Co-coerciveness. J. Fixed Point Theory Appl. 2020, 22, 1-23. [CrossRef]

7. Jolaoso, L.O.; Taiwo, A.; Alakoya, T.O.; Mewomo, O.T. Strong convergence theorem for solving pseudo-monotone variational inequality problem using projection method in a reflexive Banach space. J. Optim. Theory Appl. 2020, 185, 744-766. [CrossRef] 
8. Khan, S.H.; Alakoya, T.O.; Mewomo, O.T. Relaxed projection methods with self-adaptive step size for solving variational inequality and fixed point problems for an infinite family of multivalued relatively nonexpansive mappings in Banach spaces. Math. Comput. Appl. 2020, 25, 54. [CrossRef]

9. Marino, G.; Xu, H.K. Explicit hierarchical fixed point approach to variational inequalities. J. Optim. Theory. Appl. 2011, 149, 61-78. [CrossRef]

10. Moudafi, A. Viscosity approximation methods for fixed-point problems. J. Math. Anal. Appl. 2000, 241, 46-55. [CrossRef]

11. Alakoya, T.O.; Jolaoso, L.O.; Mewomo, O.T. A self adaptive inertial algorithm for solving split variational inclusion and fixed point problems with applications. J. Ind. Manag. Optim. 2020. [CrossRef]

12. Gibali, A.; Jolaoso, L.O.; Mewomo, O.T.; Taiwo, A. Fast and simple Bregman projection methods for solving variational inequalities and related problems in Banach spaces. Results Math. 2020, 75, 1-36. [CrossRef]

13. Izuchukwu, C.; Ogwo, G.N.; Mewomo, O.T. An Inertial Method for solving Generalized Split Feasibility Problems over the solution set of Monotone Variational Inclusions. Optimization 2020. [CrossRef]

14. Jolaoso, L.O.; Alakoya, T.O.; Taiwo, A.; Mewomo, O.T. Inertial extragradient method via viscosity approximation approach for solving Equilibrium problem in Hilbert space. Optimization 2020. [CrossRef]

15. Oyewole, O.K.; Abass, H.A.; Mewomo, O.T. A Strong convergence algorithm for a fixed point constrainted split null point problem. Rend. Circ. Mat. Palermo II 2020. [CrossRef]

16. Taiwo, A.; Owolabi, A.O.-E.; Jolaoso, L.O.; Mewomo, O.T.; Gibali, A. A new approximation scheme for solving various split inverse problems. Afr. Mat. 2020. [CrossRef]

17. Németh, S.Z. Variational inequalities on Hadamard manifolds. Nonlinear Anal. 2003, 52, 1491-1498. [CrossRef]

18. Aremu, K.O.; Abass, H.A.; Izuchukwu, C.; Mewomo, O.T. A viscosity-type algorithm for an infinitely countable family of $(f, g)$-generalized k-strictly pseudononspreading mappings in CAT( 0$)$ spaces. Analysis 2020, 40, 19-37. [CrossRef]

19. Aremu, K.O.; Izuchukwu, C.; Ogwo, G.N.; Mewomo, O.T. Multi-step Iterative algorithm for minimization and fixed point problems in p-uniformly convex metric spaces. J. Ind. Manag. Optim. 2020. [CrossRef]

20. Aremu, K.O.; Izuchukwu, C.; Ugwunnadi, G.C.; Mewomo, O.T. On the proximal point algorithm and demimetric mappings in CAT(0) spaces. Demonstr. Math. 2018, 51, 277-294. [CrossRef]

21. Bento, G.C.; Ferreira, O.P.; Oliveira, P.R. Proximal point method for a special class of non convex functions on Hadamard manifolds. Optimization 2015, 64, 289-319. [CrossRef]

22. Chen, S.L.; Huang, N.J. Vector variational inequalities and vector optimization problems on Hadamard manifolds. Optim. Lett. 2016, 10, 753-767. [CrossRef]

23. Dehghan, H.; Izuchukwu, C.; Mewomo, O.T.; Taba, D.A.; Ugwunnadi, G.C. Iterative algorithm for a family of monotone inclusion problems in CAT(0) spaces. Quaest. Math. 2020, 43, 975-998. [CrossRef]

24. Ogwo, G.N.; Izuchukwu, C.; Aremu, K.O.; Mewomo, O.T. A viscosity iterative algorithm for a family of monotone inclusion problems in an Hadamard space. Bull. Belg. Math. Soc. Simon Stevin 2020, 27, 127-152. [CrossRef]

25. Ogwo, G.N.; Izuchukwu, C.; Aremu, K.O.; Mewomo, O.T. On $\theta$-generalized demimetric mappings and monotone operators in Hadamard spaces. Demonstr. Math. 2020, 53, 95-111. [CrossRef]

26. Taiwo, A.; Jolaoso, L.O.; Mewomo, O.T. Viscosity approximation method for solving the multiple-set split equality common fixed-point problems for quasi-pseudocontractive mappings in Hilbert Spaces. J. Ind. Manag. Optim. 2017. [CrossRef]

27. Ugwunnadi, G.C.; Izuchukwu, C.; Mewomo, O.T. Strong convergence theorem for monotone inclusion problem in CAT(0) spaces. Afr. Mat. 2019, 31, 151-169. [CrossRef]

28. Khatibzadeh, H.; Ranjbar, S. A variational inequality in complete CAT(0) spaces. J. Fixed Point Theory Appl. 2015, 17, 557-574. [CrossRef]

29. Alizadeh, S.; Dehghan, H.; Moradlou, F. $\Delta$-convergence theorem for inverse strongly monotone mapping in CAT(0) spaces. Fixed Point Theory 2018, 19, 45-56. [CrossRef]

30. Osisiogu, U.A.; Adum, F.L.; Efor, T.E. Strong convergence results for variational inequality problem in CAT(0) spaces. Adv. Nonlinear Var. Inequal. 2020, 23, 84-101.

31. Izuchukwu, C.; Okeke, C.C.; Isiogugu, F.O. Viscosity iterative technique for split variational inclusion problem and fixed point problem between Hilbert space and Banach space. J. Fixed Point Theory Appl. 2018, 20, 1-25. [CrossRef] 
32. Song, Y.; Liu, X. Convergence comparison of several iteration algorithms for the common fixed point problems. Fixed Point Theory Appl. 2009, 2009, 824374. [CrossRef]

33. Bruhat, F.; Tits, J. Groupes réductits sur un cor local. In Donneés Radicielles Valueés; Institut des Hautes Études Scientifiques: Bures-sur-Yvette, France, 1972; Volume 41.

34. Kirk, W.A. Fixed point theorems in CAT(0) spaces and $\mathbb{R}$-trees. Fixed Point Theory Appl. 2004, 2004, 309-316. [CrossRef]

35. Bridson, M.R.; Haefliger, A. Metric Spaces of Non-Positive Curvature. In Fundamental of Mathematical Sciences; Springer: Berlin, Germany, 1999; Volume 319.

36. Reich, S.; Shafrir, I. Nonexpansive iterations in hyperbolic spaces. Nonlinear Anal. 1990, 15, 537-558. [CrossRef]

37. Goebel, K.; Reich, S. Uniform Convexity, Hyperbolic Geometry and Nonexpansive Mappings; Marcel Dekker: New York, NY, USA, 1984.

38. Khatibzadeh, H.; Ranjbar, S. Monotone operators and the proximal point algorithm in complete CAT $(0)$ metric spaces. J. Aust. Math. Soc. 2017, 103, 70-90. [CrossRef]

39. Aremu, K.O.; Jolaoso, L.O.; Izuchukwu, C.; Mewomo, O.T. Approximation of common solution of finite family of monotone inclusion and fixed point problems for demicontractive mappings in CAT(0) spaces. Ric. Mat. 2020, 69, 13-34. [CrossRef]

40. Berg, I.D.; Nikolaev, I.G. Quasilinearization and curvature of Alexandrov spaces. Geom. Dedicata 2008, 133, 195-218. [CrossRef]

41. Dhompongsa, S.; Panyanak, B. On $\Delta$-convergence theorems in CAT(0) spaces. Comp. Math. Appl. 2008, 56, 2572-2579. [CrossRef]

42. Dhompongsa, S.; Kirk, W.A.; Sims, B. Fixed points of uniformly Lipschitzian mappings. Nonlinear Anal. 2006, 65, 762-772. [CrossRef]

43. Kirk, W.A.; Panyanak, B. A concept of convergence in geodesic spaces. Nonlinear Anal. 2008, 68, 3689-3696. [CrossRef]

44. Dehghan, H.; Rooin, J. A characterization of metric projection in CAT(0) spaces. arXiv 2013, arXiv:1311.4174VI.

45. Dehghan, H.; Rooin, J. Metric projection and convergence theorems for nonexpansive mapping in Hadamard spaces. arXiv 2014, arXiv:1410.1137VI.

46. Chidume, C.E.; Bello, A.U.; Ndambomve, P. Strong and $\Delta$-convergence theorems for common fixed points of a finite family of multivalued demicontractive mappings in CAT(0) soaces. Abstr. Appl. Anal. 2014, 2014, 805168. [CrossRef]

47. Leustean, L. Nonexpansive iterations in uniformly convex W-hyperbolic spaces. arXiv 2013, arXiv:0810.4117.

48. Kakavandi, B.A.; Amini, M. Duality and subdifferential for convex functions on complete CAT(0) metric spaces. Nonlinear Anal. 2010, 73, 3450-3455. [CrossRef]

49. Dhompongsa, S.; Kirk, W.A.; Panyanak, B. Nonexpansive set-valued mappings in metric and Banach spaces. J. Nonlinear Convex Anal. 2007, 8, 35-45.

50. Taiwo, A.; Alakoya, T.O.; Mewomo, O.T. Halpern-type iterative process for solving split common fixed point and monotone variational inclusion problem between Banach spaces. Numer. Algorithms 2020. [CrossRef]

51. Xu, H.K. Iterative algorithms for nonlinear operators. J. Lond. Math. Soc. 2002, 66, 240-256. [CrossRef]

52. Taiwo, A.; Jolaoso, L.O.; Mewomo, O.T.; Gibali, A. On generalized mixed equilibrium problem with $\alpha-\beta-\mu$ bifunction and $\mu-\tau$ monotone mapping. J. Nonlinear Convex Anal. 2020, 21, 1381-1401.

Publisher's Note: MDPI stays neutral with regard to jurisdictional claims in published maps and institutional affiliations.

(C) 2020 by the authors. Licensee MDPI, Basel, Switzerland. This article is an open access article distributed under the terms and conditions of the Creative Commons Attribution (CC BY) license (http:/ / creativecommons.org/licenses/by/4.0/). 